\title{
Um palco de tensões e disputas: tempo presente e lembranças do passado no evangelho de Marcos
}

\author{
A scene of tensions and disputes: presente time and memories from the past in \\ Mark's gospel
}

\author{
Daniel Brasil Justi * \\ André Leonardo Chevitarese ** \\ Lair Amaro dos Santos Faria ${ }^{* * *}$
}

\begin{abstract}
Resumo
Temática de reflexões constantes em outros trabalhos e estudos publicados, o tema da memória e suas relações entre passado e presente sempre provoca releituras dos textos antigos em nossas discussões acadêmicas. Analisar o tempo presente de uma comunidade por trás de um documento antigo é, de igual forma, sempre desafiador. No entanto, no texto atual (Evangelho de Marcos), quando analisadas à luz de conceitos heurísticos - como o de memória, por exemplo - há indícios bastante eficazes na proposição de novas percepções acerca da interação constante entre memórias pretéritas e construções de memória no tempo presente (do texto que tem sido analisado). Novos horizontes se abrem no campo de estudos sobre os textos que compõem o Novo Testamento quando se dialoga com a psicologia e com as pesquisas sobre memória. Nesse sentido, esse trabalho aplica o postulado de D. L. Schacter acerca das adaptações que se realizam nas lembranças do passado para que estas atendam às necessidades do presente ao evangelho de Marcos. Conclui-se que o autor do referido evangelho reescreveu as tradições recebidas de forma que elas respondessem a questões que se lhes faziam no presente.
\end{abstract}

Palavras-chave: evangelho de Marcos; memória; paleocristianismos.

\begin{abstract}
Subject of constant reflections in other works and published studies, the theme of memory and its relations between past and present always provokes renewed perspectives regarding the readings of the ancient texts in our academic discussions. Analyzing the present time of a community behind an ancient document is likewise always challenging. However, in the present document (Mark's Gospel), when analyzed in the light of heuristic concepts - such as memory, for example - there are very effective indications in proposing new perceptions about the constant interaction between past memories and memory constructions in present times (of the ancient document that has been analysed). New horizons open up in the field of study of the texts that make up the New Testament when dialogues with psychology and research on memory. In this sense, this work applies the postulate of D.L. Schacter on the adaptations that are made in the memories of the past so that they meet the needs of the present to the gospel of Mark. It follows that the author of the said gospel rewrote the traditions received so that they answered questions that were made to them in the present.
\end{abstract}

Keywords: Mark's gospel; memory; paleo-christianities.

\footnotetext{
Artigo submetido em 15 de fevereiro de 2019 e aprovado em 30 de abril de 2019.

* Doutor em História pela UFRJ. Professor da Universidade Federal do Sul e Sudeste do Pará e Professor na UFRJ. País de origem: Brasil. E-mail: daniel_justi@hotmail.com

** Doutor em Antropologia Social pela USP. Professor titular da UFRJ. País de origem: Brasil. E-mail: andrechevitarese@yahoo.com.br

**** Doutor em História Comparada pela UFRJ. Pesquisador associado ao Laboratório de História das Experiências Religiosas do Instituto de História da UFRJ. País de origem: Brasil. E-mail: lair_amaro@yahoo.com.br
} 


\section{Introdução}

Há um pouco mais de quinze anos, Schacter (2003) analisou de forma pormenorizada um conjunto de forças que atua sobre a memória, sendo responsável por fazê-la lembrar, esquecer, interpolar ações passadas e, até mesmo, inventá-las. Um dos resultados por ele (SCHACTER, 2003, p. 171) obtidos chamounos a atenção: “[...] nossas lembranças do passado são muitas vezes reescritas para se acomodar às nossas opiniões e necessidades do presente”.

Não é a primeira vez que nos interessamos em aplicar resultados de pesquisas desenvolvidas na Psicologia em estudos relacionados ao material neotestamentário. Este retorno justifica-se, já que ele nos parece sempre bastante promissor. Neste sentido, queremos testar a validade do referido resultado, aplicando-o ao primeiro dos evangelhos escritos, isto é, a boa-nova marcana ${ }^{1}$.

Antes, porém, de testa-lo em Marcos (ver item 3) e de analisar como as suas lembranças acerca de Jesus impactam o seu processo de escrita (ver item 4), convém tecer alguns comentários sobre o que entendemos por memória (ver item 1) e por evangelho (ver item 2).

\section{Memória: considerações teóricas}

A aproximação entre os estudos sobre memória e a busca pelo Jesus histórico constitui um avanço recente e, em razão de sua incipiência, ainda precisa superar resistências e obstáculos. Alan Kirk (2005, p. 1) frisa que, não obstante a disseminação e a aplicação dos estudos sobre memória em diferentes campos das Ciências Humanas e Sociais, persiste um relativo bloqueio à sua introdução na erudição neotestamentária. Em sua visão, a contínua influência dos críticos da

\footnotetext{
${ }^{1}$ A escolha de Marcos é parcialmente aleatória, parcialmente por razões redacionais, por assim dizer, pois (i) o Evangelho de Marcos é o primeiro canônico a ser composto; (ii) é amplamente aceito na bibliografia especializada o fato de que tenha servido de base para composição de Mateus e Lucas; (iii) é fundamental para a reconstiticão do documento hipotético "Q"; e, por fim, (iv) está sit uado no tempo/espaço em um contexto em que se torna o primeiro documento sistematizado que dá conta da historicidade da vida de Jesus, fato este que promove oposição aos escritos paulinos até então de características teológicas do que se conhece como uma alta cristologia.
} 
forma deve ser responsabilizada pela marginalização da memória no âmbito da história social dos cristianismos primitivos.

Mais do que isso, ao assumir como plausível a argumentação de Crook (2013), segundo a qual os estudos sobre memória aplicados aos textos do assim chamado Novo Testamento diminuem o interesse central na recuperação das ipsissima verba Jesu, deslocando o olhar e os esforços do historiador no sentido de traçar as ipsissima structura, não é preciso muito esforço para entender as razões que levaram alguns pesquisadores mais conservadores a buscarem e a alardearem as supostas inconsistências e fragilidades dessa nova abordagem.

Com efeito, o processo de reconstrução da história social dos cristianismos, a partir do diálogo com os estudos sobre memória, tornou imperioso inferir que Jesus de Nazaré, no curso de seu ministério, proferiu inúmeras vezes e para públicos distintos a sua Boa Nova. Essa inferência deveria ser uma conclusão tácita e inquestionável. Mas, quais seriam as implicações desta conclusão? Entendemos que Jesus de Nazaré operava no âmbito de uma cultura oral, transmitindo oralmente e repetidamente suas ideias, suscitando, por conseguinte, mais de uma memória acerca de suas falas e seus feitos. Implica dizer, seria temerário postular que os autores dos evangelhos, no geral, e Marcos, no particular, registraram em seus textos exclusivamente as ipsissima verba de Jesus de Nazaré. Estudos recentes têm mostrado que as tais ipsissima verba de Jesus de Nazaré estão longe de se fazerem presentes nos chamados “textos canônicos” (FUNK et al, 1993).

Neste sentido, conferindo materialidade à experiência das pregações de Jesus de Nazaré, entendemos ser acertada a assertiva de Kelber (2002, p. 84) quando declara: 
Quando o orador carismático [Jesus de Nazaré] pronunciava um discurso em um lugar e subsequentemente escolhia enuncia-lo em outro lugar, nem ele e nem seus ouvintes podiam ter entendido essa outra exposição oral como uma versão de segunda mão da primeira. E quanto a segunda exposição, efetuada perante uma audiência diferente, com variações em relação à primeira, nem o orador e nem a sua audiência teriam pensado em diferencia-las entre um discurso primário, original, e sua versão secundária, derivada. Antes, cada proclamação era um discurso autônomo. (KELBER, 2002, p. 84).

Implica dizer, no cômputo geral o que os autores dos evangelhos verteram por escrito, com base nas memórias de testemunhas oculares ou não, foram as variações de uma mesma fala que estiveram sujeitas às peculiaridades da memória ${ }^{2}$. Cumpre, portanto, determo-nos um pouco mais demoradamente nesse aspecto, isto é, as peculiaridades da memória.

Sem sombras de dúvidas, a principal referência, de um ponto de vista sociológico, é o trabalho pioneiro de Maurice Halbwachs 3 (2003). Seu argumento central era o de que as memórias individuais deviam a sua existência às memórias coletivas de modo que o esquecimento desta ou daquela memória seria um efeito da perda de convívio com outros sujeitos com os quais um fato fora vivenciado em conjunto. Halbwachs demonstra sua proposição afirmando que, numa situação hipotética, acontece de alunos conseguirem se lembrar de seus colegas de classe, descendo a minúcias sobre os lugares que ocupavam na sala de aula, os materiais escolares que usavam, casos específicos ocorridos durante os semestres letivos e de alguns de seus professores. Porém, o pesquisador prossegue, nem sempre os professores têm a mesma recordação de seus antigos alunos no geral. Halbwachs atribui estas distinções no que tange às lembranças ao fato de os alunos poderem ter mantido vínculos após o término de sua formação escolar, encontrando-se com alguma regularidade e alimentando suas lembranças comuns, enquanto que para o professor, aquela turma de estudantes teria sido mais uma entre tantas outras com as quais trabalhou. Em outras palavras, apartado de um grupo, por qualquer razão, o sujeito tende a, gradativamente, suprimir suas lembranças adquiridas. Um

\footnotetext{
${ }^{2}$ No bojo dessa discussão, o leitor haverá de notar que os evangelhos, muito embora sejam as principais "fontes" sobre Jesus, por dependerem de memórias, estão longe de ser acurados e confiáveis historicamente.

${ }^{3}$ A discussão aqui se baseia na obra "A Memória Coletiva", publicada postumamente em 1950.
} 
possível reencontro seria capaz de reativar as memórias perdidas? Para Halbwachs, somente se algumas condições forem observadas. Se entre o sujeito e o grupo não houver mais nada em comum, não haverá nada que consiga despertar os fatos do passado. Com efeito, o trabalho do tempo em que o grupo se dispersou foi o de fazer desaparecer uma memória coletiva mais ampla que compreendia a memória do sujeito e dos demais.

No material literário do assim chamado Novo Testamento, em particular, no bojo da tradição sinótica, ocorre um caso que remete ao postulado de Halbwachs. Na Narrativa da Paixão, contida em Mc 15:214, seu autor descreve a seguinte lembrança: Requisitaram certo Simão Cireneu, que passava por ali vindo do campo, para que carregasse a cruz. Era o pai de Alexandre e de Rufo5.

Consoante o consenso acadêmico, os autores Mt e Lc utilizaram, individual e separadamente, cópias distintas de Marcos para redigirem suas versões. Se você leitor interromper neste momento a leitura deste nosso trabalho e recorrer à sua Bíblia, abrindo-a sucessivamente em Mt 27:32 e em Lc 23:26, deparar-se-á com um detalhe por demais interessante, muito embora, talvez, já não se lembre mais: ambos os evangelhos suprimiram o trecho em itálico na referida citação de Marcos.

Duas indagações emergem: (1) por que Marcos fez questão de mencionar os nomes dos filhos do homem que, de acordo com a tradição, carregou a cruz de Jesus? e (2) por que Mt e Lc, sem se conhecerem nem se citarem, decidiram eliminar de suas narrativas esta informação ${ }^{6}$.

Ao pensar com base na teorização de Halbwachs, Alexandre e Rufo seriam uma espécie de garantia da memória coletiva que a comunidade desenvolvia em torno dos detalhes da Paixão de Jesus de Nazaré. Prevenindo-se de qualquer

\footnotetext{
${ }^{4}$ Esta é a primeira citação bíblica do artigo, portanto, cabe uma explicação a respeito de seu formato. Ao longo de todo o texto optamos por utilizar o sistema de referência norte-americano (de tradição protestante) usando, assim, a separação ":" (dois pontos) e não de "," (vírgula).

${ }_{6}^{5} \mathrm{O}$ itálico é nosso.

${ }^{6}$ Pode-se aventar que as duas cópias que chegaram às mãos dos evangelistas já não continham o trecho grifado e que eles não podem ser imputados como responsáveis pela mutilação do texto que thes serviu de fonte. Isso, contudo, não altera o questionamento. Muito pelo contrário, suscita perguntar o que levou o(s) copista(s) do documento marcano que chegou às mãos dos dois evangelistas a desprezar o trecho em análise.
} 
distorção ou esquecimento da passagem, a comunidade indicava a quem procurar. Por sua vez, para as comunidades mateana e lucana aqueles dois personagens eram estranhos, cuja falta de menção não afetaria o fluxo da leitura, nem comprometeria a referência a Simão Cireneu.

Assim, seguindo o rastro de Halbwachs, cumpre salientar que a memória é um fenômeno social que, longe de ser o produto isolado de uma mente individual, é inseparável do mundo social em que a lembrança se dá. Nesse sentido, são as estruturas sociais que garantem, indispensavelmente, a real possibilidade de lembrar e esquecer no interior de grupos sociais. São tais estruturas que dão “coerência e legitimidade às memórias, arranjando-as dentro dos sistemas culturais dominantes de significado" (KIRK, 2005, p. 2).

Outra aquisição para a busca do Jesus histórico e a escrita da história da formação dos cristianismos neste diálogo com os estudos sobre memória é a constatação de que grupos, no processo de formação de suas memórias, articulam dinâmica e incessantemente o passado com um presente em permanente modificação e atravessado por diversas demandas. Assim, o que os pesquisadores sobre memória ofertam à busca pelo Jesus histórico é a constatação de que o presente dificilmente é estático e as estruturas mnemônicas estão, por conseguinte, “sujeitas, constantemente, a renovações, graduais ou radicais, à proporção que fatores externos ou internos podem mudar a existência dos grupos" (KIRK, 2005, p. 11).

\section{Evangelho: reflexões teórico-metodológicas}

O que é um evangelho? Muito embora seja uma pergunta facílima de formulação, a sua resposta está longe de sê-la. Há uma extensa bibliografia (ver, por exemplo: KOESTER, 1990, p. 1-48; BURRIDGE, 2004; HILL; KRUGER, 2012; AUNE, 2010; BROWN, 2005) que busca responder a esta questão, sem que até o momento se tenha conseguido obter qualquer consenso mínimo. Apesar de estarmos cientes dos debates envolvidos, avaliamos como necessário explicitar uma definição, até para que o leitor saiba o que entendemos por evangelho de Marcos. 
A nossa definição deriva de uma hipótese enunciada algumas décadas atrás por Ginzburg (1990, p. 21), mas que aqui ela foi completamente redesenhada, ganhando um contorno absolutamente novo7.

Evangelho seria uma arma de defesa e de ataque nas disputas entre diferentes campos religiosos ${ }^{8}$. Implica dizer: (i) este gênero literário sistematiza um momento específico, aquele instante único que não pode ser reproduzido, nem generalizado, que o seu redator tinha de $\mathrm{si}^{9}$, de sua comunidade e dos grupos religiosos externos ${ }^{10}$ com os quais ele interagiu positiva ou negativamente; (ii) este instante, delimitado por um tempo e espaço ${ }^{11}$ históricos únicos, determina a exclusividade das informações ali contidas. Em suma, estes dois vetores (tempo e espaço) constituem-se como critérios decisivos para compreender na inteireza o porquê daquela composição literária; e (iii) o seu autor (e/ou redator) ${ }^{12}$ deve ser lido como um indivíduo repleto de Deus, o que não quer dizer que ele seja a própria divindade. Enquanto sujeito histórico, ele vive na plenitude o contexto político, social, econômico e cultural ao qual está inserido.

Cabe ainda explicitar os critérios que norteiam a nossa leitura de um texto evangelho. São eles: (i) evangelho é tomado como um tipo particular de literatura que estava em circulação na bacia mediterrânica; (ii) enquanto gênero literário, ele é uma criação exclusiva do século I; (iii) ele pode ser caracterizado como uma obra particular de circulação restrita, ao menos até o século III; (iv) ele não foi originalmente concebido para ser uma espécie de bússola a indicar qual a melhor direção a ser seguida pelo seu leitor; e (v) ele não é uma obra psicografada por Deus.

\footnotetext{
${ }^{7}$ Esta hipótese foi originalmente construída por Carlo Ginzburg no contexto de acusação de feitiçaria no século XVI.

${ }^{8}$ Por campos religiosos, não tomar apenas cristãos tencionando com grupos específicos de judeus e/ou de politeístas, mas entre os próprios cristãos, os quais poderiam possuir entendimentos diferentes sobre, por exemplo, quem seria Jesus.

${ }^{9}$ Incluindo aí o seu próprio sistema de crença.

${ }^{10}$ Com seus respectivos sistemas de crenças, lidos e interpretados exclusivamente pela comunidade que está por trás do evangelho.

${ }^{11}$ Tem-se aqui um problema praticamente insuperável, haja vista a ausência completa de dados precisos sobre os locais onde os evangel hos neotestamentários foram redigidos.

12 Tomado aqui como liderança anônima naquela comunidade religiosa específica. Implica dizer, a sua autoria nos é desconhecida, sendo a atribuição do nome Marcos uma criação do século II.
} 
Cumpre, a propósito, adicionar mais uma consideração. Qual seja, o peso de autoridade e poder que textos escritos exerciam em uma cultura marcadamente oral e em transição para letrada. Pesquisadores como Shiner (2006, p. 147) advogam que, não obstante as intenções dos evangelistas, vidas de Jesus vertidas por escrito tenderam, no curso da passagem do tempo, a se verem investidas de um tipo de autoridade distinta das que possuíam as fontes orais.

A fiar-se na argumentação de Alexander (1990), porém, este processo não foi imediato ao surgimento dos primeiros relatos escritos sobre as falas e os feitos de Jesus de Nazaré, isto é, os evangelhos, suscitando, antes, tensões. Alexander formula sua hipótese, ou seja, a de que o ambiente que viu circularem os evangelhos escritos guardava uma marcada desconfiança para com a palavra escrita, preferindo a palavra falada, tomando como fundamento: (a) o contexto social em que os manuscritos ditos cristãos emergiram, a saber, o das escolas helenísticas e (b) os testemunhos de Papias e Clemente que, por sua vez, esposavam acentuado preconceito em relação à Boa Nova convertida em textos.

Alexander (1990, p. 226) mapeia a predominância da confiança na viva vox em detrimento dos livros recorrendo às citações similares de sumidades da Antiguidade greco-romana como Galeno, Aristóteles, Sêneca, Hermógenes e Cícero para postular que se criou um provérbio relacionado a isso e que a fala de Papias, por conseguinte, ecoaria a fraseologia compartilhada por aquelas personalidades. A pesquisadora, portanto, defende que mesmo após a passagem da instrução oral para o hábito da leitura, afirmar a superioridade da palavra falada sobre a palavra escrita permaneceu um lugar comum. Galeno, um dos exemplos empregados por Alexander (1990, p. 231), opunha-se a produção de livros, tida como não desejável como um fim em si mesmo à medida que eram secundários em relação ao ensino oral, meros lembretes das instruções já ministradas oralmente. Isso, contudo, não implicava na proibição expressa da publicação de livros. Os muitos livros da Antiguidade que chegaram até o presente constituem a prova disso. Havia, sim, cuidados a serem tomados e o constante reforço do discurso de uma hierarquia de valores entre a viva voz e a palavra escrita. 
Isto posto, Alexander (1990, p. 243) assevera haver uma aproximação cultural mais acentuada entre as escolas helenísticas e as igrejas cristãs do segundo século do que destas com as academias rabínicas, pois os gentios cristãos teriam vivenciado pequenas experiências diretas com aquelas. Assim, se nas escolas helenísticas valorizava-se mais os ensinos obtidos oral e diretamente com os mestres e o ato de ler textos era tido como de menor importância, imperioso se torna, conforme Alexander (1990, p. 245), que: “[reavaliemos] algumas das suposições acerca das expectativas dos autores e dos leitores dos evangelhos e, de fato, sobre as relações em geral entre textos escritos e instruções orais nas igrejas do primeiro século".

Por conseguinte, quando Papias salientava que a instrução obtida por meio de textos era menos aproveitável do que a proveniente da voz viva e durável de discípulos e de discípulos de discípulos, isso pode ser um indício de uma tensão no interior de um dos ramos do cristianismo - o que se tornou hegemônico - perante o surgimento de escritos cristãos que, assim se receava, iriam suplantar a autoridade dos oradores.

Essa questão que aqui levantamos é tão saliente que Dewey (1996) aventa, em uma perspectiva assaz interessante, que a transição da transmissão das memórias de e sobre Jesus de Nazaré do meio oral para o meio escrito resultou, sobretudo, no silenciamento de várias vozes femininas que tinham também histórias para contar. Em defesa de sua hipótese, Dewey (1996) estabelece as seguintes premissas: (a) os seguidores de Jesus e de seu movimento circulavam em um ambiente de comunicação predominantemente oral; (b) há vários indícios, na literatura antiga e em relatos de folcloristas modernos, de que mulheres podiam desempenhar o papel de contadoras de histórias e (c) tradições presentes na literatura cristã primitiva, canônica e extra canônica, suportam a noção de que mulheres foram ativas contadoras de histórias e ouvintes receptivas. Muito embora estes pressupostos, Dewey (1996, p. 72) observa: “a composição dos textos cristãos e a seleção de quais entrariam para o cânon foi o trabalho de uma minoria de letrados que, por sua vez, eram todos homens”. 
O resultado daí derivado explicaria a restrição do papel das mulheres como transmissoras da mensagem de Jesus. Com efeito, Dewey (1996, p. 74) postula que a literatura cristã primitiva apresenta indícios de dependência de tradições (ou memórias) oriundas de mulheres como narradoras de histórias. Em pelo menos três casos: a mulher com fluxo de sangue, a mulher sírio-fenícia e as mulheres que testemunharam a ressurreição de Jesus ${ }^{13}$.

Na sua reconstrução das primeiras associações cristãs, Dewey (1996, p. 74) peremptoriamente assevera que estas eram igualitárias e, quer fossem constituídas por uma mistura de sujeitos de diferentes estratos sociais quer fossem formadas predominantemente por pessoas das camadas mais pobres, "as vozes das mulheres tinham oportunidades de serem escutadas e adquiriam autoridade ao lado das vozes dos homens".

Contudo, ela (DEWEY, 1996, p. 74) prossegue, à proporção que a nova fé passou a orbitar em torno da autoridade dos manuscritos, os papeis de liderança começaram a emergir e estes, obviamente, passaram a residir nas mãos daqueles que haviam recebido educação, ou seja, homens, da elite, chefes de famílias, capazes de escrever e de ler. Uma vez mais, este processo ajudaria a explicar o trabalho de marginalização das mulheres, enquanto figuras relevantes, na disseminação da Boa Nova desde o seu princípio.

Como isso se deu? Dewey (1996, p. 76) sugere que por meio de operações sutis na maneira como as histórias envolvendo mulheres foram retrabalhadas, sendo vertidas por escrito. De acordo com seu levantamento, nos evangelhos sinóticos podem-se contabilizar dez narrativas de milagre nas quais mulheres são as recebedoras da ação incomum de Jesus de Nazaré, mas, por outro lado, trinta e três casos de milagres ocorridos com homens. Comparando-as, Dewey (1996, p. 76) assevera que as narrativas relacionadas a homens são "dois ou três versículos mais longas" do que as que retratam curas de mulheres. Mais do que isso, há um

\footnotetext{
${ }^{13}$ Acrescentaríamos aqui a narrativa da ressurreição de Lázaro, no Quarto Evangelho, que dá voz a Marta e Maria, irmãs do amigo de Jesus que se encontrava morto.
} 
desequilíbrio no que tange aos diálogos entabulados entre Jesus e aqueles por ele curados. Ou seja, Jesus troca menos palavras com elas do que com eles nos textos analisados. Ademais, "as poucas mulheres que aparecem em narrativas de milagres tendem a perder suas vozes". Com efeito, tais constatações alimentam a hipótese de Dewey de que a tradição manuscrita intencionalmente minimizou ou distorceu o papel relevante que as mulheres tinham em torno de Jesus de Nazaré conseguindo, dessa maneira, reiterar o poder masculino nas congregações cristãs.

Koester (1991) aprofunda essa discussão assumindo um ponto de vista radical. Consoante sua percepção, nos primórdios das comunidades protocristãs, o dom do Espírito possuía um caráter democratizante, à medida que todos os seus membros podiam recebê-lo. O relato, em At, no qual ocorre uma manifestação pneumática coletiva, interpretada a posteriori como um fenômeno de glossolalia, tratou-se, ao contrário do que se pensa, do registro de que, naquele tempo, o Espírito era um bem comum a todos os membros e, por consequência, um sinal de que "estruturas hierárquicas na organização comunitária" eram impensáveis (KOESTER, 1991, p. 354). Mais que isso, prossegue o autor (KOESTER, 1991, p. 354) “a possessão pelo Espírito não podia ser afirmada como privilégio de uma classe especial de sacerdotes ou profetas”, à proporção que todos os membros da comunidade de Jerusalém foram igualmente agraciados com seu derramamento.

O desenvolvimento de uma hierarquia eclesiástica, com cargos e funções destacados, implicou no fim desse, por assim dizer, empoderamento geral pelo Espírito. Com efeito, na era que se iniciava a autoridade institucional adquiriu precedência sobre as atividades inspiradas dos membros da comunidade. Koester advoga que a crescente autoridade eclesiástica de bispos, já no segundo século, foi cimentada por meio da utilização da escrita, ou melhor, através de cartas.

Assim, as cartas escritas e enviadas para as várias comunidades - inclusive as primeiras que se tem notícia: as cartas e epístolas escritas por e atribuídas a Paulo - não eram, no entendimento de Koester (1991, p. 357), “testemunhos de comunicação e edificação inspirados; antes, são instrumentos políticos elaborados 
para organizar e manter a construção social e os negócios financeiros das comunidades" as quais eram endereçadas.

Mirando, em seguida, nos textos denominados Evangelhos, Koester postula que esses documentos, tal como as cartas e epístolas, eram lidos e usados como instrumentos de “organização das comunidades cristãs primitivas” (KOESTER, 1991, p. 366). Só por isso, ou seja, por se constituírem como veículos de propaganda e instruções das igrejas em formação, é que se poderia compreender de que forma evangelhos - ele propõe como exemplo as narrativas de Mateus e de Lucas - que amalgamam conceitos cristológicos tão distintos foram aceitos ${ }^{14}$. Essa combinação de fontes que se identifica nos evangelhos, Koester sublinha, "não pode ser vista como um experimento teológico bem-sucedido, antes é a realização de uma política eclesiástica” (KOESTER, 1991, p. 367).

Em uma afirmação polêmica, Koester (1991, p. 367) enuncia que os evangelhos canônicos de Mateus e de Lucas:

Ao incorporar as tradições de duas comunidades cristãs muito diferentes em um único documento, ambas as tradições foram reconhecidas como legítimas, debalde suas divergências teológicas. Tais escritos evangélicos eram úteis, não porque dispensassem informação sobre doutrina e teologia, mas porque forneciam um manual para a ordem da igreja e para a conduta de vida dos membros da comunidade. (KOESTER, 1991, p. 367).

No que tange a adoção de quatro evangelhos pela igreja primitiva, com cristologias e narrativas marcadamente discrepantes, Koester (1991, p. 369) também enxerga a execução de um projeto de poder político. A esse processo de agregar, em um mesmo conjunto literário, os evangelhos sinóticos e o evangelho de João, o pesquisador chama de "desenvolvimento do pancristianismo" e considera inapropriados os termos “catolicismo (primitivo)” e “ortodoxia”.

\footnotetext{
${ }^{14}$ Koester refere-se à teoria das duas fontes, segundo a qual os autores dos evangelhos de Mateus e de Lucas utilizaram, na composição de seus livros, o evangelho de Marcos e o hipotético Evangelho Q. Que, por sua vez, albergam visões distintas em torno de quem foi Jesus, para que veio e porque morreu.
} 
Em suma, Alexander, Dewey e Koester, cada um à sua maneira, concordam que um evangelho não pode ser encarado inocentemente como um relato escrito das falas e feitos de Jesus de Nazaré.

\section{0 tempo presente da comunidade marcana}

Convém, agora, retornar ao resultado apresentado por Schacter (2003, p. 171): “[...] nossas lembranças do passado são muitas vezes reescritas para se acomodar às nossas opiniões e necessidades do presente”.

Diante da questão colocada, poderia se perguntar: seria possível checar "as lembranças passadas (do autor e/ou autores de Marcos)” como um processo de "reescrita para se acomodar às opiniões e necessidades do presente (do autor e/ou autores)"? A nossa resposta seria bem direta: sim, é possível reconstruir indiciariamente estas lembranças do passado, enquanto um processo de acomodação das opiniões e necessidades do tempo presente do autor e/ou autores de Marcos.

Para tanto, serão analisados cinco estudos de caso, com cada um deles revelando muita tensão e disputa, ao mesmo tempo em que deixa antever os usos do passado por parte de quem os produziu, a fim de reescreverem os seus próprios tempos presentes. 


\subsection{João cognominado Batista}

Este sujeito histórico caracteriza-se por ser uma lembrança incômoda que assombra as inúmeras comunidades cristãs nos primeiros dois séculos de cristianismo. 15

Muito embora João já estivesse morto há pelo menos trinta ou quarenta anos antes de Marcos escrever o seu evangelho, nota-se claramente o quanto ele ainda era objeto de muita tensão e disputa entre os seus seguidores ${ }^{16}$ e os seguidores de Jesus ${ }^{17}$. É no interior deste contexto que o Batista deve ser lido em Marcos:

As falas externas à comunidade marcana podem ser reconstruídas em dois momentos bem específicos: $1^{\circ}$. Mc 1:4. "João Batista esteve no deserto proclamando um batismo de arrependimento para a remissão dos pecados". $2^{\circ} . \mathrm{Mc}$ 1:9. “[...] Jesus veio de Nazaré da Galileia e foi batizado por João no rio Jordão”.

\footnotetext{
${ }^{15}$ Esse incômodo acometia não somente as comunidades cristãs primitivas, mas insiste em assombrar a historiografia moderna. Theissen e Merz (2002, p. 232), por exemplo, sublinham as marcantes diferenças entre Jesus e João, cognominado Batista, em seis tópicos: pregação do Juízo, pregação messiânica, escatologia iminente, batismo e ascese. Para esses autores (THEISSEN; MERZ, 2002, p. 234), Jesus e João devem ser vistos como contrastantes. Assim, a concepção sobre Deus já aponta essa distinção histórica. Acerca de Deus, "João enfatiza mais o aspecto da rigidez e da justiça; Jesus, o do amor e da misericórdia". Além disso, eles (THEISSEN; MERZ, 2002, p. 234) prosseguem, "no lugar do medo do juízo (com a oferta de salvação do batismo) [ou seja, a pregação de João] aparece a certeza da salvação (com uma expectativa de fundo) [isto é, a mensagem de Jesus]". James Dunn (2003, p. 447), em uma seção de seu livro justamente intitulada "As diferenças entre o Batista e Jesus", considera que os ditos sobre João atribuídos a Jesus tanto nos Sinóticos quanto no Quarto Evangelho espelham "um considerável interesse dos primeiros seguidores de Jesus acerca das relações entre ele e João". Que o leitor não se engane, Dunn está, de fato, sugerindo que as referências a João nos quatro evangelhos foram criada s no seio das comunidades surgidas após a morte de Jesus como uma espécie de atualização e correção da memória acerca da relação entre as duas figuras históricas. Porém, Dunn (2003, p. 447) vai além e aventa que, por meio de um atento escrutínio das fontes evangélicas, há como distinguir falas originais do próprio Jesus. Tais falas, por sua vez, atestariam as tentativas de Jesus no sentido "de explicar a diferença entre a sua missão e a de João". Em veemente oposição a esses e a outros autores, Fernando Bermejo-Rubio (2013) espantase diante do que lhe parece ser uma obsessiva compulsão erudita em supervalorizar os contrastes e deliberadamente negligenciar as semelhanças entre Jesus e João instaurando, por conseguinte, um padrão acadêmico no modo como abordar aquelas relações no passado. Consoante sua pesquisa pessoal, Bermejo-Rubio (2013, p. 190) infere que, em virtude desse posicionamento sobre uma notável distinção entre o Batista e Jesus poder ser identificada, especialmente em pesquisadores de orientação cristã e não e $m$ autores judeus, liberais e não cristãos, subjaz um comprometimento pura e simplesmente religioso da parte de Meier, Dunn e outros. Com efeito, uma das forças a impulsionar esses autores residiria na necessidade de ressaltar e não deixar espaço para dúvidas que Jesus foi único, um homem de "natureza incomparável", ensejando, assim, um problema, por estarem, conscientemente ou não, trazendo novamente à tona as assertivas de pesquisadores pós-bultmannianos das décadas de 1950 e 1960. Mais que isso, Bermejo-Rubio (2013, p. 191) levanta a tese que o real motivo por trás dessa apologia da diferença seria o desejo de contrastar Jesus e o Judaísmo. Conforme suas palavras, a oposição entre ambas as figuras refletiria a ainda difícil aceitação, por esses eruditos modernos, de que Jesus "foi um judeu, um completo judeu, nada além de um judeu".

${ }_{17}^{16}$ Que o viam como o verdadeiro Messias, ao invés de Jesus.

${ }^{17}$ Aqui representados pela própria comunidade marcana, para quem o Batista era, na melhor das hipóteses um predecessor do verdadeiro Messias, que era Jesus.
} 
Hoje, muito provavelmente, depois de dois mil anos de muita teologia, responsável por amarrar o Batista à história de Jesus, estas duas passagens parecem isentas de problema. No entanto, um exame mais minucioso mostra que não se deve tomá-las de forma ingênua ou marginal, na medida em que elas contêm elementos que parecem contradizer claramente a própria ideia do que vem a ser evangelho, tomado aqui enquanto gênero literário, isto é, a proclamação de uma Boa-Nova.

A primeira passagem (Mc 1:4 - ver Tabela 1a) explicita claramente que o batismo ministrado por João era de remissão de pecados, logo, só foram até ele aqueles indivíduos, homens e mulheres, que se viam como pecadores. Jesus estava entre aqueles que se dirigiram até o Jordão para viver na plenitude a metanoia.

Tabela 1a - Tempo presente de Marcos

\begin{tabular}{|l|l|l|}
\hline Grupo Religioso & \multicolumn{1}{|c|}{ Dado aceito por Marcos } & \multicolumn{1}{|c|}{ Problema da Aceitação } \\
\hline $\begin{array}{l}\text { Seguidores do } \\
\text { Batista }\end{array}$ & $\begin{array}{l}\text { João ministrava batismo para remissão } \\
\text { dos pecados }\end{array}$ & $\begin{array}{l}\text { Só foram batizados os que se } \\
\text { viram como pecadores }\end{array}$ \\
\hline & Jesus foi batizado por João & Jesus se viu como pecador \\
\hline
\end{tabular}

Fonte: Elaborada pelos autores.

A síntese destes dois passos (Mc 1:4,9) termina como uma conclusão bastante óbvia, especialmente quando tomada no contexto das violentas tensões entre diferentes grupos religiosos (ver Tabela $1 \mathrm{~b}$ ): quem seria o verdadeiro Messias: João, que redimiu Jesus de seus pecados? ou Jesus, que teve os seus pecados redimidos por João? 18

Tabela $1 \mathrm{~b}$ - Tempo presente de Marcos

\begin{tabular}{|l|l|l|}
\hline Grupo Religioso & \multicolumn{1}{|c|}{ Dado aceito por Marcos } & \multicolumn{1}{c|}{ Problema da Aceitação } \\
\hline $\begin{array}{l}\text { Seguidores do } \\
\text { Batista }\end{array}$ & $\begin{array}{l}\text { João ministrou em Jesus um batismo } \\
\text { para redimi-lo de seus pecados }\end{array}$ & $\begin{array}{l}\text { Qual dois é o Messias? João que } \\
\text { ministrou o Batismo ou Jesus que } \\
\text { recebeu o Batismo? }\end{array}$ \\
\hline
\end{tabular}

Fonte: Elaborada pelos autores.

\footnotetext{
${ }^{18}$ Claro que outra questão poderia ser aventada aqui, muito embora, neste contexto específico, ela pareceria não se enquadrar tão bem: Onde estava escrito na Torá e/ou nos livros dos Profetas e/ou ainda nos livros históricos que o Messias deveria se recon hecer pecador? Esta pergunta nunca foi plenamente respondida por Marcos, em especial porque ela nunca chegou a ser explicitamente formulada pelos grupos religiosos externos que gravitavam em torno da sua comunidade, especialmente os setores judaicos.
} 


\subsection{A família de Jesus}

São raras as informações sobre a família de Jesus no material neotestamentário, especialmente aquelas relacionadas com o seu ministério. Claro, pois, que estes dados nos remetem há pelo menos quarenta anos antes da elaboração de Marcos. Mas, a julgar pelo seu teor desconcertante, não há dúvida em afirmar que elas parecem ter sido elaboradas no lado de fora da comunidade marcana, possivelmente por grupos judaicos não especificados, "conhecedores" também de informações sobre o Nazareno. Vejamos o passo (Mc 3:20-21): E voltou para casa. E de novo a multidão se apinhou, de tal modo que eles não podiam se alimentar. E quando os seus tomaram conhecimento disso, saíram para detê-lo, porque diziam: "Enlouqueceu!".

O ponto central, objeto de disputa, é a percepção que a família carnal de Jesus tem sobre ele: trata-se de alguém que enlouqueceu e que precisa ser retido, possivelmente para tratamento (ver Tabela 2).

Tabela 2 - Tempo presente de Marcos

\begin{tabular}{|l|l|l|}
\hline Grupo Religioso & \multicolumn{1}{|c|}{ Dado aceito por Marcos } & \multicolumn{1}{c|}{ Problema da Aceitação } \\
\hline $\begin{array}{l}\text { Judeus (não } \\
\text { especificados) }\end{array}$ & $\begin{array}{l}\text { A família de Jesus diz que ele } \\
\text { enlouqueceu }\end{array}$ & $\begin{array}{l}\text { Se a sua própria família diz isto, como } \\
\text { alguém que não o conhece irá querer } \\
\text { conhecê-lo? }\end{array}$ \\
\hline
\end{tabular}

Fonte: Elaborada pelos autores.

Não é possível ler este dado sem levantar a seguinte questão: Em qual gênero literário está informação está mesmo contida? É neste ponto que a resposta se torna ainda mais constrangedora: na Boa-Nova marcana. Mas, convenhamos, este dado não tem nada de bom, pelo menos para os seguidores de Jesus, na medida em que não fornece qualquer apelo positivo, qualquer motivação que leve alguém que não o conhece a querer conhecê-lo. Ora, se a própria parentela de Jesus, que o conhece melhor do que ninguém, diz que ele enlouqueceu, como um estranho, que não o conhece, mas que lê e/ou ouve esta informação, a de querer participar da própria comunidade marcana? 


\subsection{Uso do nome de Jesus}

Há uma interessante questão em Marcos: quem pode usar o nome de Jesus? Eis o passo (Mc 9:38): Disse-lhe João: "Mestre, vimos alguém que não nos segue, expulsando demônios em teu nome, e o impedimos porque não nos seguia”.

A passagem coloca, em si, dois problemas de interpretação: de imediato, seria entender a expressão "não nos segue". Ela será tomada aqui como sinônimo de comunidade marcana, sendo esta última apresentada como a única e verdadeira interprete da mensagem de Jesus. Alguns cristãos desta comunidade estariam reivindicando a exclusividade do uso de seu nome.

O segundo problema de interpretação estaria associado ao "vimos alguém", onde a chave de leitura precisa explicitar quem seria este alguém. Pode-se admitir aqui duas possibilidades: indivíduos isolados, possivelmente não cristãos, que lançam mão do nome de Jesus para operar atos taumatúrgicos ${ }^{19}$; e/ou seguidores de Jesus, se indivíduos isolados ou comunidades religiosas, situados no ambiente externo à comunidade marcana. Neste último caso, estaríamos diante de um movimento cristão polissêmico, onde as disputas se dariam em torno de quem tem a chave de interpretação mais correta acerca da mensagem de Jesus (ver Tabela 3).

Tabela 3 - Tempo presente de Marcos

\begin{tabular}{|l|l|l|}
\hline Grupo Religioso & \multicolumn{1}{|c|}{ Dado aceito por Marcos } & Problema da Aceitação \\
\hline $\begin{array}{l}\text { Setores da } \\
\text { comunidade } \\
\text { marcana }\end{array}$ & $\begin{array}{l}\text { Politeístas e/ou judeus não poderiam utilizar o } \\
\text { nome de Jesus }\end{array}$ & $\begin{array}{l}\text { Esta prerrogativa seria } \\
\text { exclusiva dos membros } \\
\text { da comunidade } \\
\text { marcana }\end{array}$ \\
\hline & $\begin{array}{l}\text { Outros seguidores de Jesus, mas que não } \\
\text { pertenceriam à comunidade marcana, não poderiam } \\
\text { utilizar o nome de Jesus }\end{array}$ & $\begin{array}{l}\text { Esta prerrogativa seria } \\
\text { exclusiva dos membros } \\
\text { da comunidade } \\
\text { marcana }\end{array}$ \\
\hline
\end{tabular}

Fonte: Elaborada pelos autores.

\footnotetext{
${ }^{19}$ Fossem eles: curas, milagres e exorcismos.
} 
Claro está, portanto, que esta disputa não dizia respeito aos grupos religiosos externos, críticos à ideia de Jesus ser lido como Messias e/ou Filho de Deus.

Seja como for, Marcos reconheceu a existência do problema, deixando evidente que esta camada narrativa lhe era contemporânea, não tendo qualquer relação com o tempo histórico de Jesus.

\subsection{A figura de Judas}

Judas é uma invenção ${ }^{20}$ de Marcos, devendo, por isto, ser lido como uma personagem não histórica ${ }^{21}$, tamanha as contradições nela contidas. Eis um passo (Mc 14:10) que reforça este tipo de situação: Judas Iscariot, um dos Doze, foi ao chefe dos sacerdotes para entregá-lo a eles.

É evidente que esta narrativa não contém qualquer traço de Boa-Nova, muito menos traz em si qualquer fio de esperança ao leitor e/ou ouvinte de Marcos (ver Tabela 4).

\section{Tabela 4 - Tempo presente de Marcos}

\begin{tabular}{|l|l|l|}
\hline \multicolumn{1}{|c|}{ Grupo Religioso } & \multicolumn{1}{|c|}{ Dado aceito por Marcos } & \multicolumn{1}{c|}{ Problema da Aceitação } \\
\hline $\begin{array}{l}\text { Na sua inteireza, } \\
\text { a comunidade } \\
\text { marcana }\end{array}$ & $\begin{array}{l}\text { Judas, um dos Doze, decide trair Jesus, } \\
\text { entregando-o ao sumo sacerdote }\end{array}$ & $\begin{array}{l}\text { Judas é não apenas a caricatura do } \\
\text { judeu, como representa todo o povo } \\
\text { judaico. }\end{array}$ \\
\hline
\end{tabular}

Fonte: Elaborada pelos autores.

Aos olhos da comunidade marcana, os judeus, como os verdadeiros Judas, foram os únicos responsáveis pela morte de Jesus. Os romanos, representados por Pilatos, tentam desesperadamente por salva-lo (Mc 15:14): "Mas que mal ele fez? Mas, diante deste questionamento, os judeus gritaram com mais veemência (Mc 15:14): Crucifica-o!”

\footnotetext{
${ }^{20}$ Para um aprofundamento das discussões em torno de Judas, ver: Chevitarese $(2006 ; 2008 ; 2017)$.

${ }^{21}$ Paulo nunca a conheceu, nunca soube de alguém que fizesse parte do círculo mais íntimo de Jesus, denominado de Doze, tê-lo traído. Neste particular, seria oportuno que o leitor lesse neste exato momento 1Cor 15:5.
} 
Vê-se, então, formar um pequeno esboço sobre a origem da comunidade marcana: ela demonstra não conhecer informações mínimas sobre as tradições religiosas judaicas, assim como ela parece desconhecer minimamente a geografia das regiões vizinhas a Israel ${ }^{22}$. Ao mesmo tempo, há um interessante indício em Marcos (2:4), onde o teto da casa não era dotado de telhas ${ }^{23}$, o que parece sugerir a inserção de sua comunidade em uma pequena cidade, distante de uma estética mais helenizada. Estes dados parecem indicar que a comunidade marcana tem a sua origem em ambiente politeístas, onde a maior parte de seus membros, senão todos, nunca tiveram contato com o judaísmo.

Isto poderia explicar a história da traição, responsável pelo início da construção de um fosso, que com o passar dos séculos, tornou-se intransponível, mantendo em cada uma de suas margens judeus e cristãos. Em suma, esta memória marcana deve ser entendida como uma arma de ataque que ela utilizou na luta contra o um de seus principais opositores: os judeus.

\subsection{Jesus, irremediavelmente só}

O cenário em que se insere este tópico em Marcos, pode ser descrito como um desdobramento da ação de Judas de entregar Jesus ao sumo sacerdote. Jesus e seus discípulos estão no Getsêmani, quando uma multidão chega para prendê-lo. Neste momento, há um princípio de confusão, com um dos seus discípulos chegando a decepar a orelha de um servo do sumo sacerdote. Rapidamente a situação é controlada pelas forças enviadas por aqueles que controlavam o Templo de Jerusalém. Neste exato momento da narrativa, Marcos (14:50) escreve: Então, abandonando-o, fugiram todos.

O chão desta narrativa reside num acontecimento por demais constrangedor: todos os discípulos escolhidos pessoalmente por Jesus fugiram, claro, com exceção de Judas, que o havia traído. Jesus se viu irremediavelmente só

\footnotetext{
${ }^{22}$ Para estes dois aspectos centrais, recomenda-se aqui a leitura de Mc 5:1-43.

${ }^{23}$ Uma ausência percebida pelo autor de Lc $(5: 19)$, que ao ler este passo marcano fez a devida adaptação em seu texto, adaptando a casa à realidade de sua comunidade, provendo-a de telhado.
} 
diante de seus inimigos Vê-se aqui delinear duas possibilidades de leitura (ver Tabela 5).

Tabela 5 - Tempo presente de Marcos.

\begin{tabular}{|l|l|l|}
\hline Grupo Religioso & \multicolumn{1}{|c|}{ Dado aceito por Marcos } & \multicolumn{1}{c|}{ Problema da Aceitação } \\
\hline $\begin{array}{l}\text { Judeus não } \\
\text { especificados }\end{array}$ & $\begin{array}{l}\text { Os discípulos abandonam } \\
\text { Jesus }\end{array}$ & $\begin{array}{l}\text { Os discípulos salvaram suas vidas, deixando } \\
\text { para trás o seu Mestre e Senhor. }\end{array}$ \\
\hline $\begin{array}{l}\text { A comunidade } \\
\text { marcana }\end{array}$ & $\begin{array}{l}\text { Os discípulos abandonam } \\
\text { Jesus }\end{array}$ & $\begin{array}{l}\text { Os cristãos marcanos permanecem firmes ao } \\
\text { lado de Jesus }\end{array}$ \\
\hline
\end{tabular}

Fonte: Elaborada pelos autores.

$1^{\mathrm{a}}$. Esta informação pode ter surgido no lado de fora da comunidade marcana, sendo originada em algum ambiente judaico. Neste caso, ela poderia ser interpretada como uma arma de ataque utilizada pelos opositores ao movimento de Jesus; e

$2^{\mathrm{a}}$. Esta informação procede da própria comunidade marcana. Neste caso, a ênfase residiria em demonstrar que os Doze eram ignorantes, ao contrário dos cristãos marcanos, lidos como os verdadeiros discípulos de Jesus.

\section{As lembranças do passado}

Os cinco tópicos explicitaram os usos do passado por parte dos grupos religiosos externos e/ou a própria comunidade marcana, como forma de eles reescreverem os seus próprios tempos presentes.

Chegou o momento de inverter a lógica e observar como as lembranças de Marcos sobre Jesus se inserem em um processo de reescrita, como forma de acomodar às suas opiniões e necessidades.

\subsection{João cognominado Batista}

Observou-se, no ambiente marcano, que falar de João implicava trazer à tona uma memória incômoda acerca do batismo de Jesus. Este era um problema que o autor de Marcos precisou enfrentar, não apenas para sustentar os seus 
irmãos de fé, como também para fortalecê-los em suas ações missionárias - caso viessem a encontrar com os discípulos de João.

Marcos (1:2-3) abre a sua Boa-Nova citando Is, indiscutivelmente utilizado como discurso de autoridade, a fim de deixar claro, por meio de uma exegese muito própria, que o mensageiro a que o profeta se refere era João, sendo aquele que veio preparar o caminho do Senhor, lido como sendo o próprio Jesus (ver Tabela 6a).

Tabela 6a - Tempo presente de Marcos

\begin{tabular}{|c|c|c|}
\hline Grupo Religioso & A Leitura de Marcos & Uma Outra Interpretação \\
\hline $\begin{array}{c}\text { Comunidade } \\
\text { Marcana }\end{array}$ & Exegese de Is & João como mensageiro \\
\hline & Exegese de Is & Jesus como Senhor \\
\hline
\end{tabular}

Fonte: Elaborada pelos autores.

Não deixa de ser interessante notar, ainda no campo desta exegese, como Marcos (1:7) reelabora uma fala própria dos discípulos do Batista - os quais mencionavam a vinda de um ischyróteros, sem que, no entanto, especificassem quem ele seria - dando-lhe um novo contorno, isto é, dizendo que seria Jesus este ser mais forte que João seria Jesus, de quem o Batista não seria digno de desatar a correia de suas sandálias (ver Tabela 6b).

Tabela 6b - Tempo presente de Marcos

\begin{tabular}{|c|c|c|}
\hline Grupo Religioso & A Leitura de Marcos & Uma Outra Interpretação \\
\hline $\begin{array}{l}\text { Comunidade } \\
\text { Marcana }\end{array}$ & $\begin{array}{l}\text { Exegese sobre o discurso dos discípulos } \\
\text { de João }\end{array}$ & Jesus é o ischyróteros \\
\hline & $\begin{array}{l}\text { Exegese sobre o discurso dos discípulos } \\
\text { de João }\end{array}$ & $\begin{array}{l}\text { João não é digno de desatar a } \\
\text { correia das sandálias de Jesus }\end{array}$ \\
\hline
\end{tabular}

Fonte: Elaborada pelos autores.

Por fim, Marcos (1:8) estabelece uma comparação simples e direta: o batismo de João era algo menor, pois ele batizava com água, enquanto que o de Jesus era completo, já que o Espírito Santo se fazia presente - muito provavelmente o mesmo batismo ministrado pela liderança marcana em sua comunidade (ver Tabela 6c). 
Tabela 6c - Tempo presente de Marcos

\begin{tabular}{|l|l|l|}
\hline \multicolumn{1}{|c|}{ Grupo Religioso } & A Leitura de Marcos & \multicolumn{1}{c|}{ Uma Outra Interpretação } \\
\hline Comunidade Marcana & A comparação & O batismo de João é com água \\
\hline & A comparação & O batismo de João é com o Espírito Santo \\
\hline
\end{tabular}

Fonte: Elaborada pelos autores.

Mas, o ponto alto ocorre no momento em que Marcos (1:10-11) lança mão de lembranças do passado, como forma de acomodar opiniões e necessidades do seu tempo presente. Torna-se evidente, nesse exercício mnemônico, a necessidade de esvaziar por completo o discurso dos discípulos do Batista sobre os acontecimentos que cercam o batismo de Jesus. Nesta sua lembrança, não há lugar para a História. Marcos dá primazia à linguagem teológica, em particular, no momento em que ele observa que Jesus, ao subir da água, viu os céus se rasgando e o Espírito, como uma pomba, descer até ele, e uma voz - a do seu Pai, o próprio Deus, criador de todas as coisas - veio dos céus: "Tu és o meu Filho amado, em ti me comprazo" (ver Tabela 6d).

Tabela 6d - Tempo presente de Marcos

\begin{tabular}{|c|c|c|}
\hline Grupo Religioso & A Leitura de Marcos & Uma Outra Interpretação \\
\hline Comunidade Marcana & Lembranças do Passado & A História interpretada sob a ótica teológica \\
\hline
\end{tabular}

Fonte: Elaborada pelos autores.

Observa aqui um tipo padrão, que irá se repetir de maneira sistemática: o autor do evangelho lança mão de lembranças do passado, onde ele diz, como se tivesse em mãos documentos que registrassem a experiência real, um testemunho literal do próprio Jesus, sobre aquilo que ele viu e ouviu. Desta forma, estas lembranças ganham mesmo contorno de reescrita para acomodar as opiniões e necessidades de Marcos no seu tempo presente. 


\subsection{A família de Jesus}

Em uma rara informação sobre a parentela de Jesus, lê-se que ela está espantada com suas atitudes: para a sua família, ele enlouqueceu e precisa ser retido ou mantido preso em casa.

Esta informação, produzida provavelmente por algum grupo judaico, deve ser lida como uma experiência mnemônica que é reescrita para acomodar as opiniões do grupo que a produziu. Não é aqui relevante analisar se essa lembrança é verdadeira ou falsa. $O$ interessante é que Marcos parece admiti-la como portadora de algum tipo de veracidade, pois ele não a enfrentou seriamente.

A julgar por outros documentos, tais como a Epístola de Tiago, ${ }^{24}$ Jo (7:5) e Hegesipo, citado por Eusébio ( $\mathrm{HE}^{25}$ 3.9:1), pode-se conjecturar que estivesse em curso, a partir da segunda metade do século I e o século II, uma tentativa dos parentes de Jesus assumirem o controle do movimento de Jesus. Isto explicaria, por exemplo, o deslocamento da ideia de família consanguínea para aqueles que fazem a vontade de Deus, tal como propõe Marcos (3:31-35) (ver Tabela 7).

Tabela 7 - Tempo presente de Marcos.

\begin{tabular}{|l|l|l|}
\hline \multicolumn{1}{|c|}{ Grupo Religioso } & \multicolumn{1}{|c|}{ A Leitura de Marcos } & \multicolumn{1}{c|}{ Uma Outra Interpretação } \\
\hline Comunidade Marcana & $\begin{array}{l}\text { Aceita em parte crítica feita por } \\
\text { setores judaicos }\end{array}$ & $\begin{array}{l}\text { Os parentes carnais de Jesus não } \\
\text { são a sua verdadeira família }\end{array}$ \\
\hline Comunidade Marcana & Mudança o sentido de família & $\begin{array}{l}\text { Família é quem faz a vontade de } \\
\text { Deus }\end{array}$ \\
\hline
\end{tabular}

Fonte: Elaborada pelos autores.

Mas, percebe-se aqui como o autor do evangelho lança mão de lembranças, neste caso, palavras de Jesus, como uma forma de reescrita, a fim de acomodar às suas opiniões e necessidades do tempo presente, portanto, uma resposta à família de Jesus.

\footnotetext{
24 Um dos ditos irmãos de Jesus, cuja percepção teológica apresenta tons contrários àqueles contidos no material paulino, especialmente aquele que diz (Tg 2:18-19): “De fato, alguém poderá objetar-lhe: Tu tens fé e eu tenho obras. Mostra-me a tua fé sem obras e eu te mostrarei a fé pelas minhas obras. Tu crês que há um só Deus? Ótimo! Lembra-te, porém, que também os demônios creem, mas estremecem".

${ }^{25}$ EUSEBIUS. The Ecclesiastical History. With an English translation by Kirsopp Lake. Vol. I. Loeb Classical Library. London: Harvard University Press, 1926.
} 


\subsection{Uso do nome de Jesus}

Como observado, esta questão diz respeito à própria comunidade marcana, onde algum setor, diríamos hoje, mais fundamentalista, demandava um exclusivismo do uso do nome ${ }^{26}$ do Senhor, tendo como pano de fundo o fato de ele ter poder.

Um procedimento que se mostra recorrente em Marcos é o seu discurso de autoridade, baseado em suas lembranças do passado, em particular, a sua capacidade de recordar as palavras do Senhor. Neste caso, "Jesus" coloca-se contrário ao pleito daquele setor marcano, tal como pode ser observado no seguinte passo (Mc 9:39-40; ver Tabela 8): “Não o impeçais, pois não há ninguém que faça um milagre em meu nome e logo depois passa falar mal de mim. Porque quem não é contra nós é por nós”.

Tabela 8 - Tempo presente de Marcos.

\begin{tabular}{|l|l|l|}
\hline Grupo Religioso & A Leitura de Marcos & $\begin{array}{l}\text { Uma Outra } \\
\text { Interpretação }\end{array}$ \\
\hline Liderança Marcana & $\begin{array}{l}\text { Refuta a ideia de exclusividade no uso do nome de } \\
\text { Jesus }\end{array}$ & $\begin{array}{l}\text { Quem não é contra } \\
\text { nós é por nós }\end{array}$ \\
\hline
\end{tabular}

Fonte: Elaborada pelos autores.

Em suma, a liderança por detrás da autoria do evangelho lança mão de lembranças, neste caso, ele é capaz de recordar as próprias palavras de Jesus, onde elas ganham contornos de reescrita para acomodar às suas opiniões e necessidades do tempo presente. Por meio deste procedimento, refuta-se uma demanda interna, através de um discurso de autoridade, não da liderança, mas do próprio Jesus.

\footnotetext{
${ }^{26}$ Coube ao redator final do evangelho de Marcos, que, inclusive, acrescentou um novo final ao texto (a partir de Mc 16:9), como forma de equacionar o problema deixado pelo autor do texto (Mc 16:8), explicitar o poder do nome Jesus: "[...] em meu nome expuls arão demônios, falarão em novas línguas, pegarão em serpentes, e se beberem algum veneno mortífero, nada sofrerão; imporão as mãos sobre os enfermos, e estes ficarão curados".
} 


\subsection{A figura de Judas}

Judas é uma personagem tão repleta de contradições, que se torna muito difícil a sua admissibilidade histórica. Até mesmo o exercício mnemônico de Marcos, ao recuperar as palavras de Jesus (Mc 14:21), só ampliam os problemas em torno desta personagem: Mas, ai daquele homem por quem o Filho do Homem for entregue! Melhor seria para aquele homem não ter nascido.

A fala soa como desconcertante, tal como apontou Erhman (2006, p. 93): se Judas não tivesse tomado a decisão de trair Jesus, este último não teria sido preso, crucificado e morto e sepultado. Por conseguinte, a inação de Judas acarretaria a não ressuscitação de Jesus, nem a sua ascensão aos céus (ver Tabela 9).

Tabela 9 - Tempo presente de Marcos.

\begin{tabular}{|l|l|l|}
\hline Grupo Religioso & Dado aceito por Marcos & Problema da Aceitação \\
\hline Comunidade marcana & Judas é amaldiçoado por Jesus & $\begin{array}{l}\text { Judas jamais pode escolher outro } \\
\text { caminho, senão o da traição }\end{array}$ \\
\hline
\end{tabular}

Fonte: Elaborada pelos autores.

Em suma, Judas Iscariot veio ao mundo com um destino pré-estabelecido um caso único em toda a história do cristianismo -, sem qualquer possibilidade de poder escolher um outro caminho, salvo aquele de ser o traidor de Jesus.

\subsection{Jesus, irremediavelmente só}

Na narrativa da prisão de Jesus, é interessante observar, que enquanto todos os seus discípulos fugiram, deixando-o completamente só diante de seus inimigos, a presença de um jovem envolto a um lençol. Ele até tentou segui-lo, mas, quando os soldados o viram e tentaram prendê-lo, ele se desembaraçou do lençol e fugiu $\mathrm{nu}^{27}(\mathrm{Mc}$ 14:51-52).

\footnotetext{
${ }^{27}$ Sobre as implicações deste jovem nu, que Mt e Lc literalmente ignoram de suas narrativas, no centro de um evangelho secreto de Marcos, que constituiria um terceiro texto (o primeiro seria o próprio autor; enquanto que o segundo aquele produzido pelo re dator) que a tradição eclesiástica atribuiu a Marcos, ver: Smith (1973).
} 
Se esta narrativa foi originada fora ou dentro da comunidade marcana, ela tem consequências sobre a dinâmica dos acontecimentos seguintes à prisão de Jesus (ver Tabela 10).

Tabela 10. Tempo presente de Marcos.

\begin{tabular}{|l|l|l|}
\hline Grupo Religioso & Dado aceito por Marcos & Problema da Aceitação \\
\hline $\begin{array}{l}\text { Judeus não } \\
\text { especificados }\end{array}$ & Os discípulos abandonam Jesus & $\begin{array}{l}\text { Ausência de testemunhas sobre o que se } \\
\text { seguiu após a prisão de Jesus }\end{array}$ \\
\hline $\begin{array}{l}\text { A comunidade } \\
\text { marcana }\end{array}$ & Os discípulos abandonam Jesus & $\begin{array}{l}\text { Ausência de testemunhas sobre o que se } \\
\text { seguiu após a prisão de Jesus }\end{array}$ \\
\hline
\end{tabular}

Fonte: Elaborada pelos autores.

Normalmente elas não são consideradas, mas, como saltam aos olhos, ao menos algumas delas serão aqui explicitadas: Como Marcos soube o que ocorreu com Jesus diante do Sinédrio? Como ele soube o que aconteceu com Jesus diante de Pilatos? De onde vieram as informações sobre a crucificação de Jesus? Como ele soube dos detalhes que culminaram na morte de Jesus? As respostas a todas estas questões devem ser buscadas exclusivamente na Teologia, nunca na História.

\section{Conclusão}

À guisa de conclusão, duas referências interessantes podem comparecer na discussão desenvolvida no presente texto. A primeira delas é a de Crossan (1998, p. 20): “A história é o passado reconstruído interativamente pelo presente através das evidências discutidas no discurso público”. A segunda, não menos importante, é aquela que discute questões hermenêuticas quando da aproximação de qualquer texto escrito por parte de um leitor. Trata-se do texto de Umberto Eco (1993, p. 79104). O que o intelectual italiano apresenta é uma discussão assaz interessante acerca da sede do sentido em um texto: no seu autor, no seu leitor ou na literalidade do próprio texto.

Neste sentido, o presente estudo concordou com Crossan ao perceber, conceitualmente, como se dá a operação (ou experiência de agentes históricos) cotidiana no sentido de atender a demandas contextuais e absolutamente concretas 
de uma audiência/comunidade que constantemente lê, relê e atualiza suas experiências (sejam elas de fé ou não). Ainda que a "leitura" se dê por meio da reivindicação de memória(s) oral (is), ainda sim é uma leitura.

E história, no sentido que pretendido por Crossan, ganha limites plenamente definidos em torno das discussões sobre memórias. A sua definição para história não circunscreve a noção de memória como única, mas a evoca no momento em que articula passado e presente. No presente trabalho trechos evangélicos e memórias específicas foram abordadas. Entretanto, cabe uma distinção metodológica fundamental para o leitor(a) mais desatento(a): o texto dos Evangelhos, por si só, já é o produto de profundas interações entre passado (eventos "recordados") e presente (respostas definidas e sistematizadas de forma escrita como registros de memória).

Logo, o que se entende, por exemplo, na Teologia (talvez não na exegese) como verdade presenciada por testemunhas oculares, ou seja: o texto, é, antes de tudo, o resultado de interações de memória entre um passado e as respostas do tempo presente para demandas contextuais. Assim, entre o evento fundante, que chamaríamos aqui "vida e experiências históricas de Jesus” e as recensões escritas que se conhece, hoje, por Evangelho, atuou uma operação histórica decisiva, conforme demonstrada no texto.

Agora, inevitavelmente, outra questão se abriria para a discussão, justamente aquela proposta pelo autor italiano: onde está a "verdade" de um texto? No seu(s) autor (es), nas intenções do(a) leitor(a) ao se aproximar do texto/memória ou no conteúdo direto do próprio texto/memória e suas estruturas? Para o último caso, se o que se tem em vista são memórias não escritas, deve-se reconhecer que as reflexões teóricas de Eco não contemplaram essa possibilidade. 
Entretanto, a questão permanece: quem detém a última palavra sobre o evento que chega ao conhecimento do ouvinte/leitor? A depender da escolha epistemológica que se empreenda estará na estrutura ou forma da memória/texto, uma vez que estratégias comunicativas foram decisivamente empenhadas para que aquele evento sobrevivesse no formato recebido pelos ouvintes/leitores do tempo presente. Porém, se o caminho adotado é asseverar que a "verdade" encontra-se no(a) agente histórico(a) que a recebe e a ressignifica, bem, neste caso, a verdade venceu na forma com a qual esse tempo presente instrumentalizou a memória. E, por fim, se o que se busca é a versão compreendida pelo(s) autor(es) da memória/texto, buscá-la torna-se um imperativo!

Esta busca, para os tempos atuais, empreendida por meio da ciência restará nada mais do que um critério plausível de verdade, mas nunca uma verdade absoluta. E, no caso dos exemplos analisados neste trabalho parece claro que a comunidade que recebeu tais memórias/textos entendeu estar o evento irremediavelmente perdido, logo, a correta hermenêutica se faz a partir do seu próprio tempo presente. Cumpre então observar que (i) a ipsissima verba Jesu está irremediavelmente perdia, exceto pelos critérios de verdade plausíveis que a ciência é capaz de apontar; e (ii) experiências de agentes históricos são sempre plurais. Será seu tempo, espaço e, portanto, condições materiais de experiência que conferirão validade e verdade àquilo que será assumido como verdade. E jamais caberá, pelo menos à ciência, deliberar uma singularidade ou versão “oficial”.

\section{REFERÊNCIAS}

ALEXANDER, L. The living voice. Scepticism towards the written Word in early Christian and in Graeco-Roman texts. In: CLINES, D. J. A.; FOWL, Stephen E.; PORTER, Stanley E. (Eds.). The Bible in three dimensions: essays in celebration of forty years of biblical studies in the University of Sheffield. Journal for the Study of the Old Testament, Sheffield, v. 87, p. 226-237, 1990.

AUNE, D. E. (Ed.). The Blackwell companion to the New Testament. Chichester: Wiley-Blackwell, 2010. 
BERMEJO-RUBIO, F. Why is John the Baptist used as a foil for Jesus? Leaps of faith and oblique anti-Judaism in contemporary scholarship. Journal for the Study of Historical Jesus, Leiden, v. 11, n. 2, p. 170-196, jan. 2013.

BROWN, R. E. Introdução ao Novo Testamento. São Paulo: Paulinas, 2005.

BURRIDGE, R. A. What are the Gospels? A comparison with Graeco-Roman biography. 2.ed. Grand Rapids: William B. Eerdmans Publishing Company, 2004.

CHEVITARESE, A. L. Da traição à morte de Jesus de Nazaré. Em torno de Judas Iscariotes. In: CHEVITARESE, A. L.; CORNELLI, G.; SELVATICI, M. (Org.). Jesus de Nazaré. Uma outra história. São Paulo: Annablume, 2006. p. 121-130.

CHEVITARESE, A. L. Cristianismos. Questões e debates metodológicos. Rio de Janeiro: Kline, 2016.

CHEVITARESE, A. L. Evangelho de Judas: uma luz no fim de uma antiga história? In: FUNARI, P. P. A.; SILVA, G. J.; MARTINS, A. L. (Org.). História antiga. Contribuições brasileiras. São Paulo: Annablume, 2008. p. 65-77.

CHEVITARESE, A. L. Malhações oitocentistas. Cultura popular e significados locais na queima e malhação do boneco de Judas. In: Chevitarese, A. L.; Gomes, F. S. (Org.). Entre pedaços e camadas. Histórias e arqueologias do Rio de Janeiro, séculos XVIII-XXI. Rio de Janeiro: 7Letras, 2017. p. 115-129.

CHEVITARESE, A. L.; CORNELLI, G. Judaísmo, cristianismo, helenismo. Ensaios sobre interações culturais no Mediterrâneo antigo. São Paulo: Annablume; FAPESP, 2007.

CROOK, Z. Collective memory distortion and the quest for historical Jesus. Journal for the study of the historical Jesus, Leiden, v. 11, n. 1, p. 53-76, jan. 2013.

CROSSAN, J. D. The birth of Christianity. San Francisco: Harper San Francisco, 1998.

DEWEY, Joanna. From storytelling to written text: the loss of early Christian Women's voices. Biblical Theology Bulletin: Journal of Bible and Culture, Thousand Oaks, v. 26, n. 2, p. 71-78, 1996.

DUNN, J. D. G. Jesus remembered. Grand Rapids: William B. Eerdmans Publishing Company, 2003.

ECO, U. Entre autor e texto. In: ECO, U. (Org.) Interpretação e superinterpretação. São Paulo: Martins Fontes, 1993. p. 79-104.

EHRMAN, B. D. Christianity turned on its head. The alternative vision of the gospel of Judas. In: KASSER, R.; MEYER, M.; WURST, G. The gospel of Judas. Washington: National Geographic, 2006. p. 77-120.

FARIA, L. A. S. Quem vos ouve, ouve a mim: oralidade e memória nos cristianismos originários. Rio de Janeiro: Kliné, 2011. 
FUNK, R. W. et al. The five gospels. The search for the authentic words of Jesus. What did Jesus really say? New York: Maxwell Macmillan International, 1993.

GINZBURG, C. Sinais. Raízes de um paradigma indiciário. In: GINZBURG, C. Mitos, emblemas e sinais. Morfologia e história. São Paulo: Companhia das Letras, 1990. p. 143-179.

HALBWACKS, M. A memória coletiva. São Paulo: Centauro, 2003.

HILL, C. E.; KRUGER, M. J. (Ed.). The early text of the New Testament. Oxford: Oxford University Press, 2012.

KELBER, W. H. The case of the gospels: memory's desire and the limits of historical criticism. Oral tradition, Columbia, v. 17, n. 1, p. 55-86, 2002.

KIRK, A.; THATCHER, T. (Ed.). Memory, tradition, and text: uses of the past in early Christianity. Atlanta: Society of Biblical Literature, 2005.

KOESTER, H. Writings and the spirit: authority and politics in ancient Christianity. The Harvard Theological Review, Cambridge, v. 84, n. 4, p. 353-372, 1991.

KOESTER, H. Ancient Christian gospels. Their history and development. London: SCM Press, 1990.

SCHACTER, D. L. Os sete pecados. Como a mente esquece e lembra da memória. Rio de Janeiro: Rocco, 2003.

SHINER, W. Memory technology and the composition of Mark. In: HORSLEY, R. A., DRAPER, J. A., FOLEY, J. M. (Ed.). Performing the gospel: orality, memory, and Mark. Minneapolis: Fortress Press, 2006. p. 147-165.

SMITH, M. Clement of Alexandria and a secret gospel of Mark. Cambridge: Harvard University Press, 1973.

THEISSEN, G.; MERZ, A. O Jesus histórico. Um manual. São Paulo: Loyola, 2002. 